\title{
Factors Affecting Social Media Adoption Among SMEs in Jakarta
}

\author{
Nico Hartanto ${ }^{1}$ Lydiawati Soelaiman ${ }^{1 *}$ \\ ${ }^{1}$ Faculty of Economics and Business, Universitas Tarumanagara, West Jakarta, DKI Jakarta, Indonesia, 11470 \\ *Corresponding author. Email: lydiawatis@fe.untar.ac.id
}

\begin{abstract}
At this time, SMEs are required to understand and study technological developments in adopting social media to improve business performance. In practice, social media adoption is influenced by several factors. For this reason, the purpose of this study is to obtain empirical evidence regarding whether the technological context, organizational context, and environmental context positively affect social media adoption. The sample was taken by using purposive sampling technique. An online questionnaire was used to obtain the data with SME owners characteristics who use social media. The data collected were 103 samples. The results of this study indicate that organizational context and environmental context positively affect social media adoption, but technological context does not positively affect social media adoption on SMEs in Jakarta.
\end{abstract}

\section{Keywords: Environmental context, organizational context, technological context, social media adoption}

\section{INTRODUCTION}

SMEs have several roles in the Indonesian economy, such as the formation of Gross Domestic Product (GDP), expansion of job opportunities, and provision of safety nets for low-income people. The presence of SMEs can help people in various regions to meet their needs so that economic equality in various corners can be achieved. SMEs also contribute to foreign exchange for the country by exporting goods and services abroad [1]. In addition, SMEs contribute to reducing poverty and unemployment by opening up new jobs [2].

Currently, Indonesia has entered the 4.0 industry where SME players are required to understand and study existing technological developments. One of the uses of technology that can be used is social media adoption. In practice in the field, social media adoption is influenced by several factors. Several previous studies have shown that factors such as technological, organizational, and environmental context positively and significantly affect social media adoption [3], [4], [5], [6].

Technological context can develop associations through social media with customers, partners, suppliers, colleagues, and competitors so that business networks can develop [3]. The use of social media adoption is applied to interact with consumers such as discussing products or services offered [5]. Previous research has shown a positive and significant correlation within technological context and social media adoption [4].

Apart from technological context, organizational context positively and significantly affects social media adoption. The social media implementation needs a top management mandate so that supervisors can use social media in their calculated or marketing performance [7]. Therefore, top management's support for innovation significantly affects social media usage [3]. This finding is the same with the results of earlier finding which show that organizational context positively and significantly affected social media adoption [8].

Furthermore, the environmental context also positively and significantly affects social media adoption in accordance with the finding of earlier research [9]. The commitment to implement social media in work is primarily affected by the environmental context such as clients, rivals, and the public [6]. Environmental context such as competition, customers, and social pressure has become an important factor in determining social media adoption [5].

This exploration was conducted with aim of testing empirically whether the technological, organizational, and environmental context positively affect social media adoption on small-medium enterprises at Jakarta. Results of the study are expected to support SME players to develop their business more broadly by utilizing a technological context to develop business networks, pay attention to organizational context in supporting business activities and understand the environmental context in identifying external factors in optimizing social media adoption so that in the end it can improve business performance. 


\section{LITERATURE REVIEW AND HYPOTHESIS}

\subsection{Technological Context}

All technologies which are applied and accessible through company and considered to be possibly worthwhile, although is not yet used are called technological context [7]. In addition, other research states the technological context strongly affects small medium enterprises' usage of enterprise applications [10]. Based on the definition of the technological context above, it can be concluded that the technological context is a number of technologies that are available and can be used by a business or company because it can provide high benefits or uses such as improving business performance, adapting to existing situations, and competing in the market.

\subsection{Organizational Context}

The inner aspects of the enterprise are called organizational context [8]. Furthermore, the organizational context contains the entire enterprise aspects such as the workers, total revenues, and management system and its assets such as the workers and their connection and chain [7]. Based on the definition of organizational context above, it can be concluded that organizational context is a descriptive measurement related to the internal characteristics of a company such as the workers or staffs, networks, total revenues, company coverage, management system and company size.

\subsection{Environmental Context}

All those elements outside the company are called environmental context [7]. Furthermore, the environmental context emphasize on fields in which the organization performs its business practices, with an emphasis on outside elements affecting the sector that have direct effects on the company, such as government stimulus and legislation[11]. Based on the definition of the environmental context above, it can be concluded that the environmental context is a company's external environmental factors that impact the company and affect the industry, such as areas where the company conducts business operations, incentives, and government regulations.

\subsection{Social Media Adoption}

Online tools that individuals use to exchange content are called social media: pictures, photographs, ideas, text, perspectives, video, satire, opinion, gossip, and news [12]. Besides that, social media also called Web 2.0, acts as a giant tool for the enterprises including SMEs to improve their business [13]. Derived from the explanation above, conclusion could be drawn social media adoption is the application of an important tool or resource for a company or business to introduce their identity to the public, share information, communicate goods and customer service, interact to consumers by sharing content through videos, photos, images, text, ideas, insights, humor, opinions, gossip and news.

\subsection{The Correlation within Technological Context and Social Media Adoption}

The technology context is very important because it can improve a company's ability to apply social media with the aim of developing associations with customers, partners, suppliers, colleagues and competitors so that business networks can develop [3]. The use of technologies like social media will provide strong advantages while handling and shaping connection within consumers, colleague, workers, also promoting inside outside communication [4]. There are several previous studies that tested the relationship between these two variables, which said that the technological context had a positive and significant role in social media adoption [4]. In addition, the results of other studies can prove the correlation within technological context and social media adoption [5]. Derived from the explanation above, the first hypothesis $\left(\mathrm{H}_{1}\right)$ is:

$\mathrm{H}_{1}$ : Technological Context positively affects Social Media Adoption.

\subsection{The Correlation within Organizational Context and Social Media Adoption}

The application of social media in the organization requires a mandate from the top-down management so that managers can incorporate social media in their calculated or marketing performance [7]. Top management also mandates the adoption of social media to staff in carrying out operational and marketing activities [8]. There have been several previous studies that tested the relationship between these two variables, which said that organizational context positively and significantly affects social media adoption [3]. In addition, the results of other studies can prove the correlation between organizational context and social media adoption [7]. Derived from the explanation above, the second hypothesis $\left(\mathrm{H}_{2}\right)$ is:

$\mathbf{H}_{2}$ : Organizational Context positively affects Social Media Adoption.

\subsection{The Correlation within Environmental Context and Social Media Adoption}

In the business world, the commitment to apply social media is largely influenced through environmental contexts such as customers, competitors, and society [6]. Environmental contexts such as competition, customers and social pressure have become important factors in determining social media adoption. Customers and social pressure are important factors due to changes in consumer behaviour and consumer purchasing decision processes 
through the result of technology and social media. Apart from it, competition is also an important factor as many businesses are turning to online channels to compete with other competitors [5]. The correlation between these two variables has been examined in many earlier research, which say that environmental context positively and significantly affects social media adoption [9]. In addition, the results of other studies can prove the correlation within environmental context and social media adoption [6]. Derived from the explanation above, the third hypothesis $\left(\mathrm{H}_{3}\right)$ is:

$\mathrm{H}_{3}$ : Environmental Context positively affects Social Media Adoption.

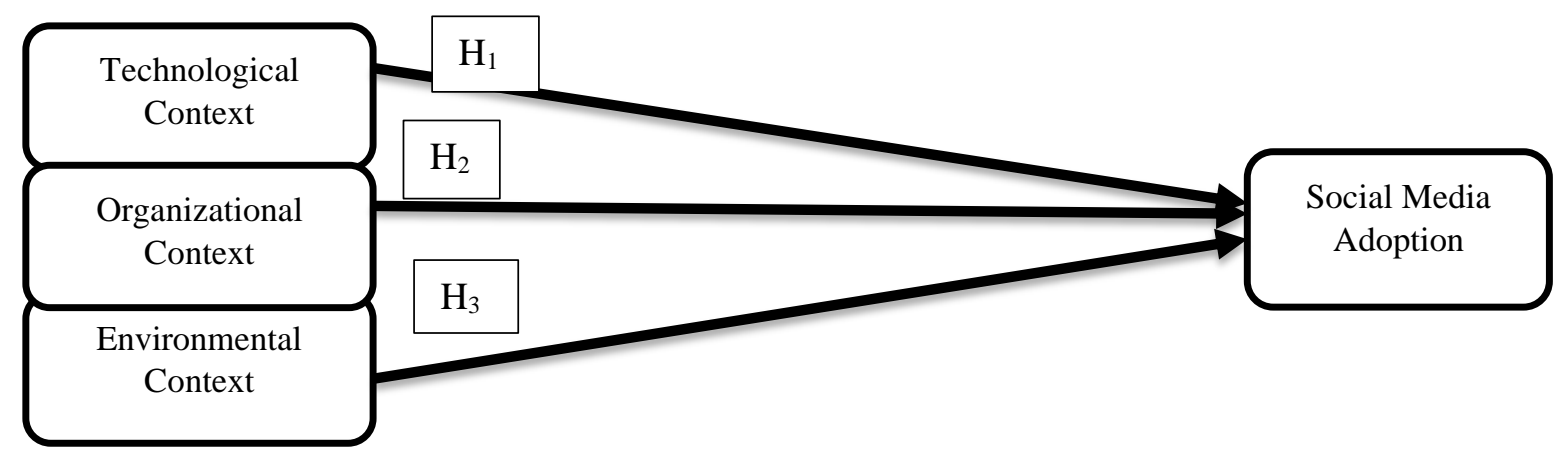

Figure 1 Research Framework

\section{RESEARCH METHODOLOGY}

In this research, the method used is quantitative research using a descriptive research design. Specifically, this study uses a descriptive research design because it wants to describe facts about population systematically and accurately. This study used data collection cross sectional, where data collection was only done once. An online questionnaire was used to obtain the data. Non-probability sampling is used in this study. Non-probability sampling is a sampling technique which the probability or chances in every sample to be chosen is unknown [16]. The sample was taken by using purposive sampling technique. Purposive sampling is a method in which the sample is restricted to a certain type of group, because they have the specific criteria needed by the researcher [17]. Specific criteria in this study are having a small-medium enterprise located in Jakarta and using social media. The sample in this study are 103 owners of small-medium enterprises (SMEs) in Jakarta who apply social media. The sample size is based on Rosco's statement about the ideal sample which is above 30 and below 500 samples [17]. From 103 respondents studied, the majority of respondents business were in West Jakarta, with 81 respondents (78.6\%), 61 people $(59.2 \%)$ had just started their business in less than one year, the majority of respondents with 51 people (49, $5 \%$ ) owns a business in food \& beverage sector, and based on the social media used, it was found that $95.1 \%$ used Instagram in adopting social media. The following is a table regarding the variables and the number of indicators that will be used and processed in this study:

Table 1. Variable Measurement Indicators

\begin{tabular}{|l|c|c|c|}
\hline No. & \multicolumn{1}{|c|}{ Variable } & Indicators & Source \\
\hline 1. & Technological Context & & [8], [3], [7], [5], [13], [14], [15]. \\
& $-\quad$ Relative Advantage & 6 & \\
& $-\quad$ Compatibility & 4 & \\
& $-\quad$ Complexity & 5 & {$[9],[3],[7],[8]$.} \\
& $-\quad$ Triability & 4 & {$[7],[8],[9],[4],[5],[3]$.} \\
\hline 2. & Organizational Context & 6 & \\
\hline 3. & Environmental Context & 4 & \\
& $-\quad$ Competitive Industry & 4 & \\
& $-\quad$ Bandwagon Pressure & 4 & \\
\hline 4. & Social Media Adoption & 7 & \\
\hline
\end{tabular}




\section{RESULT AND DISCUSSION}

Based on the results of the convergent validity analysis, it can be found that the finding of Average Variance Extracted (AVE) in every variable is bigger than 0.5 so that based on the results of the test, the AVE from every variable is categorized as valid. In addition, it can also be obtained that the value of loading factor on each indicator is greater than 0.5 so that based on the results of the test, loading factor on all variables are categorized as valid. Derived from the findings of discriminant validity analysis, conclusion can be drawn that the value of the Heterotrait-Monotrait Ratio (HTMT) on each variable is smaller than 1 so derived from the finding of HeterotraitMonotrait Ratio (HTMT) all variables categorized as valid. In addition, the results of the analysis can also be obtained by cross loading which shows that all indicators have a higher loading factor than the cross loading value. This shows that all indicators used in this study are categorized as valid.

Derived from the findings of the reliability analysis, conclusion can be drawn, finding of cronbach alpha in every variables are bigger than 0.7 . It indicates the measuring instruments of the variables are technological, organizational, environmental context, and social media adoption categorized as reliable. Then, it can also be concluded that the value of composite reliability in each variable is greater than 0.7 which indicates that the measuring instruments of the variables are technological, organizational, environmental context, and social media adoption categorized as reliable.

Based on the results of path coefficient, carried out to determine the correlation within independent variable and dependent variable whether it is weak or strong, it can be concluded in accordance with the results below: that organizational context is a variable that has the largest coefficient value and has a positive direction that affects social media adoption by 0.353 . Then, the environmental context is the variable that has the second largest coefficient value and has a positive direction that affects social media adoption by 0.336 . Then, technological context is a variable that has the smallest coefficient value and has a positive direction which affects social media adoption by 0.126 .

Table 2. Hypothesis Testing Result (t-statistics)

\begin{tabular}{|l|c|c|c|c|}
\hline \multicolumn{1}{|c|}{ Hypothesis } & $\begin{array}{c}\text { Path } \\
\text { Coefficient }\end{array}$ & t-statistics & $p$-value & Finding \\
\hline $\begin{array}{l}\mathrm{H}_{1}: \text { Technological Context } \rightarrow \text { Social } \\
\text { Media Adoption }\end{array}$ & 0,126 & 1,007 & 0,314 & $\begin{array}{c}\text { Hypothesis Not } \\
\text { Supported }\end{array}$ \\
\hline $\begin{array}{l}\mathrm{H}_{2}: \text { Organizational Context } \rightarrow \text { Social } \\
\text { Media Adoption }\end{array}$ & 0,353 & 2,297 & 0,022 & Hypothesis Supported \\
\hline $\begin{array}{l}\mathrm{H}_{3}: \text { Environmental Context } \rightarrow \text { Social } \\
\text { Media Adoption }\end{array}$ & 0,336 & 2,416 & 0,016 & Hypothesis Supported \\
\hline
\end{tabular}

Based on the table above, the results show that organizational context is the variable that has the largest coefficient value and has a positive direction that affects social media adoption by 0.353 . Then, the environmental context is the variable that has the second largest coefficient value and has a positive direction that affects social media adoption by 0.336 . Then, technological context is a variable that has the smallest coefficient value and has a positive direction which affects social media adoption by 0.126 .

Based on the results of testing the first hypothesis $\left(\mathrm{H}_{1}\right)$, it shows that the Technological Context does not positively affect Social Media Adoption, so it can be concluded that the first hypothesis $\left(\mathrm{H}_{1}\right)$ is not supported. This is not in line with the research by Ramdani et al. [10] which states that the technological context is something that strongly affects if it is applied to SMEs. The results of testing this hypothesis are also not in line with the results of research conducted by Pateli et al. [3], Cao et al. [4], Tripopsakul [5] which state that Technological Context positively affects Social Media Adoption. In our study, technological context doesn't positively affect social media adoption on SMEs due to the characteristics of the majority of SME owners who have just established their business in less than one year, so they have not conducted training to apply social media technology. As the result, the social media technology usage is not optimal. Actually, when it is applied with in-depth training and knowledge about social media and it is carried out regularly, it will have great potential for the survival of SMEs itself. This thing is supported with complexity dimension that has the smallest coefficient value. In this context, complexity is related with innovation that has correlation with technological usage. Perhaps SME owners are already understand about technology to use social media. However, social media is still assumed as something difficult to use and to interact for business purpose.

Based on the results of testing the second hypothesis $\left(\mathrm{H}_{2}\right)$, it shows that Organizational Context positively affects Social Media Adoption, so it can be concluded that the second hypothesis $\left(\mathrm{H}_{2}\right)$ is supported. This is in line with the research by Alsharji et al. [7] which states that Social Media Adoption in an organization requires a mandate from top to bottom management so that managers can implement social media in their tactical or marketing operations. The results of testing this hypothesis are also in line with the results of research conducted by Ahmad et al. [8], Pateli et al. [3], Cao et al. [4] which states that Organizational Context positively affects Social Media Adoption. It explains organizational context is important 
in social media adoption for SMEs because the support of SME owners in applying social media is urgent in order to maintain continuity. Setting priorities and expectations for SME owners to apply social media, additionally understanding the risks faced from using social media is carried out so that SME owners can maintain relationships with consumers.

Based on the results of testing the third hypothesis $\left(\mathrm{H}_{3}\right)$, it shows Environmental Context positively affects Social Media Adoption, so it can be concluded that the third hypothesis $\left(\mathrm{H}_{3}\right)$ is supported. This is in line with the research by Luu et al. [6] which states that the commitment to implement social media in business is largely influenced through environmental contexts such as consumers, rivals, and the public. The results of testing this hypothesis are also in line with the results of research conducted by Tajudeen et al. [9], Tripopsakul [5], Alsharji et al. [7] which states that Environmental Context positively affects Social Media Adoption. It explains environmental context is important in social media adoption for SMEs because SME owners feel social media is a crucial tool for retaining customers and competing in the marketplace so that they can increase the competitive advantage of their business. SME owners feel that social media is a popular application and many competitors have applied social media so they decide adopting social media. Likewise current habitual customers tendency who have migrated to use social media in their daily lives.

\section{CONCLUSION AND IMPLICATIONS}

The conclusion that can be drawn from this study is that the technological context doesn't positively affect social media adoption on SMEs at Jakarta. Meanwhile organizational context, environmental context positively affect social media adoption on SMEs at Jakarta.

Researchers suggest that SME owners can optimize social media usage through adding expertise, knowledge, and indepth insights about social media technology when running their business. Management in SME is also expected to assist social media usage to maintain business continuity and adapt to existing situations. SME players are also expected to be able to maintain customers and compete in the marketplace competitively to increase business competitive advantage by understanding the environmental context. SME players are expected to be able to optimize social media adoption so that they can reach wider customers, increase customer satisfaction, and improve service quality.

\section{LIMITATION AND SUGGESTION}

Due to limitation of cost, energy, and time of this study which is relatively short, so researchers restrict the research subject which is SME owners located in Jakarta with the variables inspected are environmental context, technological context, organizational context, and social media adoption.
For further research, it is hoped that the number of samples will be increased and the coverage of the sampling area is wider so that it can reach SMEs that are outside Jakarta area so that they can represent a wider range of respondent characteristics. In addition, further research is suggested to expand research variables for instance: firm age, in order to more accurately measure their effect on social media adoption.

\section{REFERENCES}

[1] Putri, A.S. (2019, December 20). Peran UMKM dalam Perekonomian Indonesia. Kompas.com. Retrieved October 26, 2020, from https://www. kompas.com/skola/read/2019/12/20/120000469/peranumkm-dalamperekonomianindonesia?page $=$ all

[2] Sandi, F.B. (2020, June 24). Peran UMKM di Indonesia yang Perlu Anda Ketahui. Online-pajak.com. Retrieved October 26, 2020, from https://www.onlinepajak.com/seputar-pph-final/peran-umkm

[3] Pateli, A., Mylonas, N., \& Spyrou, A. Organizational Adoption of Social Media in the Hospitality Industry: An Integrated Approach Based on DIT and TOE Frameworks. Sustainability Journal, 2020, pp. 1-20.

[4] Cao, Y., Ajjan, H., Hong, P., \& Le, T. Using social media for competitive business outcomes: An empirical study of companies in China. Journal of Advances in Management Research, 15(2), 2018, pp. 211-235.

[5] Tripopsakul, S. Social Media Adoption As a Business Platform: An Integrated TAM-TOE Framework. Polish Journal of Management Studies, 18 (2), 2018, pp. 350-362.

[6] Luu, T.N., Nguyen, P.M., Dang, T.H., \& Dao, P.Q. Factors Affecting the Adoption of Social Media in Business: Evidence From Individual and Household Retailers in Vietnam. International Journal of Entrepreneurship, 23, 2019, pp. 1-16.

[7] Alsharji, A., Ahmad, S.Z., \& Abu Bakar, A.R. Understanding Social Media Adoption in SMEs: Empirical Evidence from the United Arab Emirates. Journal Of Entrepreneurship in Emerging Economies, 10(2), 2018, pp. 302-328.

[8] Ahmad, S.Z., Abu Bakar, A.R., \& Ahmad, N. Social Media Adoption and its Impact on Firm Performance: the case of UAE. International Journal of Entrepreneurial Behavior and Research, 2018, pp. 1-28. 
[9] Tajudeen, F.P., Jaafar, N.I., \& Ainin, S. Understanding the impact of social media usage among organizations. Information \& Management, 55(3), 2017, pp. 308-321.

[10] Ramdani, B., Chevers, D., \& Williams, D. SMEs' adoption of enterprise Applications. Journal of Small Business and Enterprise Development, 20(4), 2013, pp. 735-753.

[11] Ahmad, S.Z., Abu Bakar, A.R., Faziharudean, T.M., \& Mohammed Zaki, K.A. An Empirical Study of Factors Affecting E-Commerce Adoption among Small and Medium-Sized Enterprises in a Developing Country: Evidence from Malaysia. Information Technology for Development, 2014, pp. 1-18.

[12] Drury, G. Social media: Should marketers engage and how can it be done effectively? Journal of Direct, Data and Digital Marketing Practice, 9(3), 2008, pp. 274-277.

[13] Chatterjee, S. \& Kar, A. K. Why do small and medium enterprises use social media marketing and what is the impact: Empirical insights from India. International Journal of Information Management, 2020, pp. 1-13.

[14] Odoom, R., Dorson, T., \& Acheampong, G. Antecedents of social media usage and performance benefits in small- and medium-sized enterprises (SMEs). Journal of Enterprise Information Management, 30(3), 2017, pp. 383-399.

[15] Ainin, S., Parveen, F., Moghavvemi, S., \& Jaafar, N.I. Factors influencing the use of social media by SMEs and its performance outcomes. Industrial Management \& Data Systems, 115(3), 2015, pp. 570588.

[16] Rahi, S. Research Design and Methods: A Systematic Review of Research Paradigms, Sampling Issues and Instruments Development. International Journal of Economics and Management Sciences, 6(2), 2017, pp. 1-5.

[17] Sekaran, U. \& Bougie, R. Research Methods for Business: A Skill Building Approach, Seventh Edition. United Kingdom: John Wiley \& Sons Ltd, 2016. 